\title{
The DEAD-box RNA helicases and multiple abiotic stresses in plants: a systematic review of recent advances and challenges
}

\author{
Indrani Baruah, Johni Debbarma, HP Deka Boruah and Channa Keshavaiah ${ }^{*}$ \\ Biotechnology Group, Biological Sciences and Technology Division, CSIR-North East Institute of Science and \\ Technology (CSIR-NEIST), Jorhat, Assam, India
}

*Corresponding author: channakeshav@neist.res.in

\begin{abstract}
Major crop production does not yet match the population growth rate because multiple abiotic stresses hamper the growth and yield of these crops. Most of the plants can tolerate adverse climatic conditions by performing some adaptive machineries but to certain extent. Till date various biotechnological and molecular breeding research approaches have been directed towards developing resistance to single stress factor. However, development of crop plants resistant to a single stress is not an ideal solution in the current agriculture scenario. Occurrence of multiple stresses at a single point of time makes it difficult to formulate research strategies. Considering the huge loss of crop productivity due to these environmental factors, there is an urgent need to direct our research focus towards developing sustainable multi-stress resistance in plants to counter the adverse effect of climate change on the productivity of crops. RNA helicases are ubiquitous proteins that are found in both prokaryotes and eukaryotes. The largest RNA helicase family comprises the DEAD-box RNA helicases which are involved in many aspects of RNA metabolism and in diverse biological processes in plants including regulation of multiple abiotic stress responses. The DEAD-box RNA helicases can be considered as means to identify pathways involved in multiple abiotic stress tolerance. In this review, we summarize the recent advances in elucidating the functions of the DEAD-box RNA helicases in multiple abiotic stress responses and future challenges. We also briefly discussed about our recent research efforts (published and on-going) in this direction. This review would help to formulate new research endeavours utilizing the DEAD-box helicase genes in development of multiple abiotic stress tolerant plants through genetic engineering and biotechnology. Target specific multiplex and multigene CRISPR/Ca9 genome editing would be ideal approach to edit different abiotic stress responsive DEAD-box RNA helicase genes to develop sustainable multiple abiotic stress tolerance in crop plants.
\end{abstract}

Key Words: Arabidopsis, AtSKD1, Brassica napus, CRISPR/Cas9, DEAD-box, dehydrins, RNA helicases, multiple abiotic stresses, negative regulation.

Abbreviations: STRS_stress response suppressor; CIPs_cold induced proteins; eIF_eukaryotic initiation factor; AtSKD1_ Arabidopsis thaliana suppressor of $\mathrm{K}^{+}$transport growth defect1; TF_transcription factor.

\section{Introduction}

Plants are the primary producers in which all living organisms are dependent for their vital necessities for survival. But the gradual disparities of climatic factors in environment have caused severe damage to crop productivity. Abiotic stress is a major cause for low crop productivity. Although there are some plants which can tolerate or escape the stress environment, but most of the major crops are sensitive to abiotic stress conditions. Plants mediate some defensive mechanism to endure the unpleasant surrounding conditions. In these mechanisms several stress responsive genes, proteins and few other transcriptional factors coordinate with each other to confer abiotic stress tolerance to the plant without affecting the yield and productivity.

\section{RNA helicases}

Helicase enzymes are energy dependent double stranded nucleotides responsible for unwinding of DNA or RNA (Jankowsky, 2011; Andreou and Klostermeier, 2013). Molecular processes such as replication, transcription, posttranscriptional modification, translation, mRNA splicing and
mRNA export and its stability are vital for living organisms, and helicase enzymes are to play very crucial role in gene expression and regulation (Hartman et al., 2006; Bolinger et al., 2007; Bolinger et al., 2010; Górna et al., 2010; Ranji et al., 2011; Andreou and Klostermeier, 2013; Chu et al., 2016; Lin et al., 2016; Padmanabhan et al., 2016). Helicase enzymes are categorized into two types namely, DNA helicase and RNA helicase (Jankowsky, 2011). DNA helicases were of main focus in late 1970's but RNA helicases were not discovered till 1980. In 1988, T.C. Hodgeman and Eugene Koonin discovered some viral RNA proteins that unwind RNA during viral replication which was later considered as RNA helicase enzyme (Jankowsky and Fairman-Williams, 2010) (Fig. 1). RNA helicases participate in alteration in conformation of ribonucleotides, RNPs, mRNP assembly and pre-mRNA splicing (Hartman et al., 2006; Jankowsky, 2011; Owttrim, 2013; Mallam et al., 2014; $\mathrm{Ma}$ et al. 2016). RNA helicases also plays essential role in cell signaling against viral infection by activating interferons and cytokines through phosphorylation of the transcription factors (Jankowsky et al., 2011). There are six major families 
of RNA helicases (Jankowsky et al., 2011; Hardwick and Luisi, 2013; Leitão et al., 2015). The RNA helicases are included in superfamily2 (SF2) that comprises of three subfamilies (Tanner and Linder, 2001; Owttrim, 2006; Jankowsky, 2011; Owttrim, 2013; Jarmoskaite and Russell, 2014). DEAD-box RNA helicase is one of those important subfamilies. eIF4A is the first protein which was demonstrated as a helicase that can unwind RNA strands during viral replication (Linder et al., 1989; Chan et al., 2004; Koroleva et al., 2009a; Bush et al., 2015). Helicase enzymes especially from SF1 and SF2 super families are very much well known for their conserved amino acid domains or helicase core, and they are named as per their conserved helicase cores (Jankowsky and Fairman, 2007; FairmanWilliams et al., 2010). A number of studies have revealed the molecular structure, biochemical nature and physiological function of RNA helicases (Linder and Jankowsky, 2011). The conserved helicase core is present in the cleft between two Recombinase protein (Rec-A) like domains (Linder and Jankowsky, 2011) (Fig. 2). RNA helicases use the energy released from breakage of nucleotide bonds during ATP hydrolysis for unwinding of RNA duplex (Jankowsky and Fairman, 2007; Jankowsky and Putnam, 2010; Jankowsky, 2011; Mallam et al., 2014). As these conserved sequences play essential role in ATP or other NTP hydrolysis, mutation in these sequences may cause inhibition of unwinding activity of helicase enzymes and participation of other proteins like RNA binding proteins in various molecular mechanisms (Fairman-Williams et al., 2010). Most of the RNA helicases may have sequence similarity or may have similar helicase core but they are functionally distinct (Fairman-Williams et al., 2010). Besides conformational changes of RNA duplex, RNA helicases are also involved in abiotic stress responses in plants (Owttrim, 2006; Koroleva et al., 2009a; Khan et al., 2014; Liu et al., 2016). Recently, the DEAD-box RNA helicases have been extensively studied in model and crop plants to explore their functional utilities to develop multiple abiotic and biotic stress resistance.

\section{The DEAD-box RNA helicases}

DEAD-box RNA helicases belong to SF2 superfamily which bear a conserved helicase core (Ranji and Boris-Lawrie, 2010; Hardwick and Luisi, 2013). DEAD- box helicase are named so as their conserved motif comprises of amino acid sequences of Asp-Glu-Ala-Asp (D-E-A-D) (Linder et al., 1989; Owttrim, 2006; Fairman-Williams et al., 2010; Ranji and Boris-Lawrie, 2010; Linder and Jankowsky, 2011; Putnam and Jankowsky, 2013). There are two Rec-A (Recombinase protein) like domain with a central hinge region in DEAD-box helicase and the helicase core is present in between the two domains (Fig. 2) (Linder and Jankowsky, 2011). Rec-A like domain interacts with phosphate backbone of the RNA duplex and this interaction does not provide base recognition specificity (Owttrim, 2006; Jankowsky and Fairman, 2007; Linder and Jankowsky, 2011; Hardwick and Luisi, 2013). ATP dependent RNA unwinding and RNA dependent ATP hydrolysis by DEAD-box helicases are controlled by Q motif (Linder and Jankowsky, 2011) (Fig. 2). A lot of studies have been carried out to explain the RNA duplex unwinding by DEAD-box helicase enzymes. The ATP binding motif and RNA binding motif of DEAD-box helicase enables it to switch from open to close conformation to complete the cycle of ATP hydrolysis, and release of unwound RNA strand (Jankowsky and Fairman, 2007; Jankowsky, 2011; Jankowsky et al., 2011; Andreou and Klostermeier, 2013). As soon as the ATP binds to the ATP binding motif, and RNA binds to RNA binding motif, the DEAD-box protein transiently changed from open conformation into closed one. The conformational changes destabilize the RNA duplex and dissociate the first RNA strand (Fairman-Williams et al., 2010; Jankowsky, 2011). The protein complex retains closed conformation during ATP hydrolysis but as soon as the phosphate is released from the motif, it turns into open conformation and the second RNA strand is released. Thus, the cycle repeats by addition of new ATP and RNA duplex to the DEAD-box protein (Jankowsky and Fairman, 2007; Jankowsky and Putnam, 2010; Andreou and Klostermeier, 2013).

The eIF4A (eukaryotic initiation factor 4A) has been considered as the model protein of the DEAD- box proteins as it had been demonstrated as the first protein having helicase activity to unwind RNA duplex (Hilbert et al., 2011; Andreou and Klostermeier, 2013; Pascuan et al. 2016; Andreou et al., 2017). Later, Patrick Linder and coworkers showed that many proteins shared conserved helicase motif homology with eIF4A. D-E-A-D amino acid sequence motif had been found to be highly shared by many proteins and hence a new group of proteins were identified and named as the DEAD-box proteins (Linder and Jankowsky, 2011; Andreou and Klostermeier, 2013). The DEAD-box helicases are available in prokaryotes as well in eukaryotes. Some of the DEAD- box helicases have been found to be involved in annealing of nucleotide duplex by both ATP dependent and independent manners (Yang et al., 2005; Yang et al., 2007; Pyle, 2008; Liu et al., 2014). The DEAD box proteins Ded1 and Mss116 anneal RNA strands without using energy input (Halls et al., 2007; Mohr et al., 2008), whereas cyanobacterial CrhR is ATP-dependent nucleotide annealer (Ruminski et al., 2016). Some DEAD-box helicases reform RNA structure by removing the unnecessary proteins to avoid the block in functional RNA assembly. C. elegans DEAD-box gene DDX-23 which is a homologue of P68 human DEAD-box gene plays important role in mi-RNA processing (Chu et al., 2016). DEAD-box RNA helicases including DbpA, DRH1 and P68 related RNA helicase genes are broadly involved in chromosome breakage, RNA and protein biogenesis (Childs et al., 2016; McDaniel et al., 2016; Jao et al., 2017). Dbp5 yeast DEAD-box RNA helicase is a homolog DDX19 from Homo sapiens that has been reported to involved in translation termination. DDX19 and Gle1 which is a regulator of RNA-dependent DEAD-box ATPase proteins have been found to be involved in mRNA export and protein biosynthesis (Mikhailova et al., 2017; Jao et al., 2017). Though DEAD-box RNA helicases performs ATP dependent RNA duplex unwinding, there are some DEAD-box RNA helicases which do not require ATP to unwind RNA. eIF4A in human and DbpA protein from Escherichia coli has been reported to have ATP dependent RNA helicase activity whereas CsdA (cold shock protein) from Escherichia coli has been found to be ATP independent RNA helicase (Ando and Nakamura, 2006; Childs et al. 2016). CsdA, a DEAD-box protein has also been shown to be involved in 23S rRNA precursor processing and nonsense mediated mRNA decay (Ando and Nakamura, 2006; Lehnik-Habrink et al., 2013). AtRH9 DEAD-box RNA helicase has been found to involved in promotion of Turnip Mosaic Virus Replication by facilitating proteolytic cleavage of TuMV polyprotein ( $\mathrm{Li}$ et al., 2016). Therefore, AtRH9 knockdown can be used as a preventive solution against TuMV viral infection. Usually viral mRNAs are 5'-capped containing structured 5'-UTRs, and therefore they are eIF4A-dependent for translation. Recently a natural compound silvestrol, which act as an active inhibitor of eIF4A has been isolated from Aglaia 
Table 1. Some of the DEAD-box RNA helicase genes showing their functional role in stress responses in plants

\begin{tabular}{|c|c|c|c|}
\hline DEAD-box genes & Source & Role in abiotic stress response & References \\
\hline TOGRI & Oryza sativa & $\begin{array}{l}\text { Regulates thermos-tolerant growth as pre-rRNA } \\
\text { chaperon }\end{array}$ & (Wang et al., 2016) \\
\hline SIDEAD30 & $\begin{array}{l}\text { Solanum } \\
\text { lycopersicum }\end{array}$ & Regulates tolerance to salt stress & (Zhu et al., 2015) \\
\hline SIDEAD31 & $\begin{array}{l}\text { Solanum } \\
\text { lycopersicum }\end{array}$ & $\begin{array}{l}\text { Regulates tolerance to multiple stress including salt, } \\
\text { drought and cold stress }\end{array}$ & (Zhu et al., 2015) \\
\hline HVDl & Hordeum vulgare & Confers tolerance to both salt and cold stress & (Macovei et al., 2012) \\
\hline AtRH3 & $\begin{array}{l}\text { Arabidopsis } \\
\text { thaliana }\end{array}$ & $\begin{array}{l}\text { Regulates proper intron splicing through its RNA } \\
\text { chaperon activity, chloroplast function, } 50 \text { s ribosome } \\
\text { biogenesis and tolerance to cold and salt stress }\end{array}$ & $\begin{array}{l}\text { (Macovei et al., 2012; Gu et } \\
\text { al., 2014) }\end{array}$ \\
\hline$O s A B P$ & Oryza sativa & $\begin{array}{l}\text { Regulates tolerance to salt, dehydration, } \mathrm{ABA} \text {, blue, red } \\
\text { light stress treatment and other stress responsive protein } \\
\text { function. }\end{array}$ & (Macovei et al., 2012) \\
\hline OsBIRHI & Oryza sativa & $\begin{array}{l}\text { Regulates oxidative stress tolerance in OsBIRH1 } \\
\text { transgenic plants and enhance the expression of } \\
\text { oxidative stress tolerance related genes like AtApx1, } \\
\text { AtApx2, and AtFSD1 }\end{array}$ & (Li et al., 2008) \\
\hline $\begin{array}{l}\text { DRH1 / DEAD box } \\
\text { ATPase }\end{array}$ & $\begin{array}{l}\text { Arabidopsis } \\
\text { thaliana }\end{array}$ & Regulates tolerance to the extreme low temperature & (Mahajan and Tuteja, 2005) \\
\hline OsBIRHI & Oryza sativa & $\begin{array}{l}\text { Confers tolerance to oxidative stress and pathogenic } \\
\text { infections }\end{array}$ & (Li et al., 2008) \\
\hline$O s A B P$ & Oryza sativa & $\begin{array}{l}\text { Confers tolerance to saline condition, } \mathrm{ABA} \text { treatment, } \\
\text { dehydration condition, red and blue light }\end{array}$ & (Macovei et al., 2012) \\
\hline LOS4 & $\begin{array}{l}\text { Arabidopsis } \\
\text { thaliana }\end{array}$ & $\begin{array}{l}\text { Responsible for cold induced gene regulation and } \\
\text { confers chilling tolerance }\end{array}$ & $\begin{array}{l}\text { (Vashisht et al., 2005; } \\
\text { Owttrim, 2006) }\end{array}$ \\
\hline AtRH7 & $\begin{array}{l}\text { Arabidopsis } \\
\text { thaliana }\end{array}$ & $\begin{array}{l}\text { Regulates cold induced gene expression and act as } \\
\text { RNA chaperon }\end{array}$ & (Huang et al., 2016) \\
\hline P68 & Pisum sativum & $\begin{array}{l}\text { Regulate pre-mRNA processing, splicing and confers } \\
\text { cold adaptation }\end{array}$ & (Tuteja et al., 2014) \\
\hline $\mathrm{CrhC}$ & $\begin{array}{l}\text { Cyanobacterium } \\
\text { Anabaena }\end{array}$ & $\begin{array}{l}\text { Involves in rRNA and polysome preparation, Regulates } \\
\text { unwinding of secondary structure of 5' UTR of RNA } \\
\text { under cold stress condition }\end{array}$ & (Yu and Owttrim, 2000) \\
\hline $\mathrm{CbDRH} 2$ & $\begin{array}{l}\text { Chorispora } \\
\text { bungeana }\end{array}$ & $\begin{array}{l}\text { Confers cold stress tolerance by interacting with } \\
\text { CbGRP (cold responsive glycine rich RNA binding } \\
\text { protein) }\end{array}$ & (Yang et al., 2014) \\
\hline
\end{tabular}

Table 2. List of the DEAD-box genes and transcription factors showing positive or negative regulation in abiotic stress responses

\begin{tabular}{|c|c|c|c|}
\hline $\begin{array}{l}\text { DEAD-box genes/ } \\
\text { TFs }\end{array}$ & Source & $\begin{array}{l}\text { Nature of } \\
\text { regulation }\end{array}$ & Reference \\
\hline AtRH7 & Arabidopsis thaliana & Positive & (Huang et al., 2016; Liu et al., 2016) \\
\hline P68 & Pisum sativum & Positive & (Tuteja et al., 2014) \\
\hline strs 1 & Arabidopsis thaliana & Negative & (Kant et al., 2007; Khan et al., 2014) \\
\hline strs 2 & Arabidopsis thaliana & Negative & $\begin{array}{c}\text { (Kant et al., 2007; Barak et al., 2014; Khan et } \\
\text { al., 2014) }\end{array}$ \\
\hline AtRH3 & Arabidopsis thaliana & Positive & (Macovei et al., 2012; Gu et al., 2014) \\
\hline$C B F 1$ & Arabidopsis thaliana & Positive & (To et al., 2011) \\
\hline$D R E B 1 A / C B F 3$ & Arabidopsis thaliana & Positive & (Zhao et al., 2007) \\
\hline ALY4 & Arabidopsis thaliana & Positive & (Koroleva et al., 2009b; Teng et al., 2014) \\
\hline SIDEAD31 & Solanum lycopersicum & Positive & (Zhu et al., 2015) \\
\hline SIDEAD30 & Solanum lycopersicum & Positive & (Zhu et al., 2015) \\
\hline$H V D 1$ & Hordeum vulgare & Positive & (Macovei et al., 2012) \\
\hline AtRH9 & Arabidopsis thaliana & Positive & (Huang et al., 2016) \\
\hline$H D 2 C$ & Arabidopsis thaliana & Positive & (To et al., 2011; Luo et al., 2012) \\
\hline DRD1 & Arabidopsis thaliana & Negative & (To et al., 2011; Khan et al., 2014) \\
\hline DC13 & Arabidopsis thaliana & Negative & (To et al., 2011; Khan et al., 2014) \\
\hline$R D R 2$ & Arabidopsis thaliana & Negative & (To et al., 2011; Khan et al., 2014) \\
\hline CBF5 & Arabidopsis thaliana & Negative & (Khan et al., 2014) \\
\hline AGO4 & Arabidopsis thaliana & Positive & (Khan et al., 2014) \\
\hline eIF4A & Arabidopsis thaliana & Positive & $\begin{array}{c}\text { (Koroleva et al., 2009a; Koroleva et al., } \\
\text { 2009b) }\end{array}$ \\
\hline$D D B 1$ & Arabidopsis thaliana & Positive & (Ly et al., 2013) \\
\hline LHP1 & Arabidopsis thaliana & Positive & (Exner et al., 2009; Khan et al., 2014) \\
\hline$R D 29 A$ & Arabidopsis thaliana & Positive & (Bihmidine et al., 2013) \\
\hline AtCSP3 & Arabidopsis thaliana & Positive & (Liu et al., 2016) \\
\hline TOGRI & Oryza sativa & Positive & (Wang et al., 2016) \\
\hline
\end{tabular}




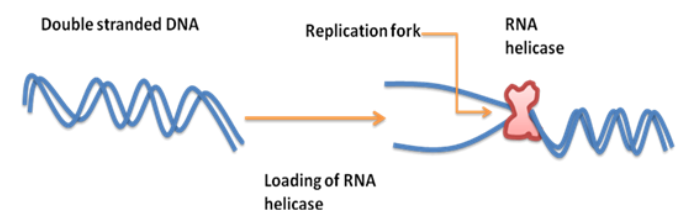

Fig 1. RNA helicase unwinds double stranded RNA during viral RNA replication. RNA proteins that unwind RNA during viral replication (RNA helicase enzymes). RNA helicases participate in alteration in conformation of ribonucleotides, RNPs, mRNP assembly and pre-mRNA splicing.

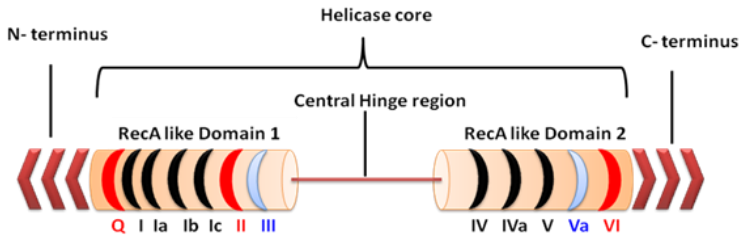

Fig 2. Schematic representation of the DEAD-box helicase core structure: The DEAD-box helicase core is comprised of RecA like domain 1 and RecA like domain2 which is linked through a central hinge region. There are 12 motifs (Q, I, Ia, Ib, II, III, IV, Iva, V, $\mathrm{Va}$ and VI) distributed in two domains. Motifs in red color are involved in ATP binding and hydrolysis, black colored are involved in RNA binding and blue colored are involved in both RNA binding and ATP hydrolysis. The DEAD-box helicase core is flanked by $\mathrm{N}$ - and C-terminal extensions that give RNA-protein interaction specificity. Modified from (Linder and Jankowsky, 2011).

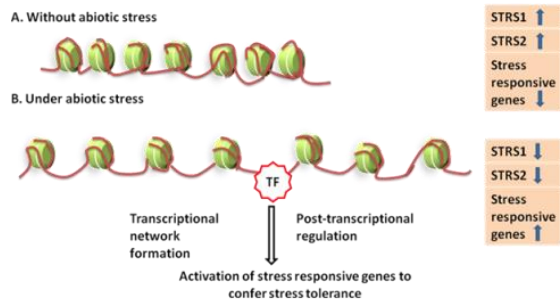

Fig 3. Effects of abiotic stress in chromatin structure. A. Without abiotic stress chromatin structure remain in closed inactive and differentiation state (heterochromatin). Over-expression of STRS1 and STRS2 inhibits the expression of stress responsive genes through RNA directed DNA methylation (RdDM). B. Under abiotic stress chromatin structure is turned into open active and dedifferentiation state (euchromatin). Down-regulation of STRS1 and STRS2 enhances the expression of stress responsive gene. Modified from (Barak et al., 2014).

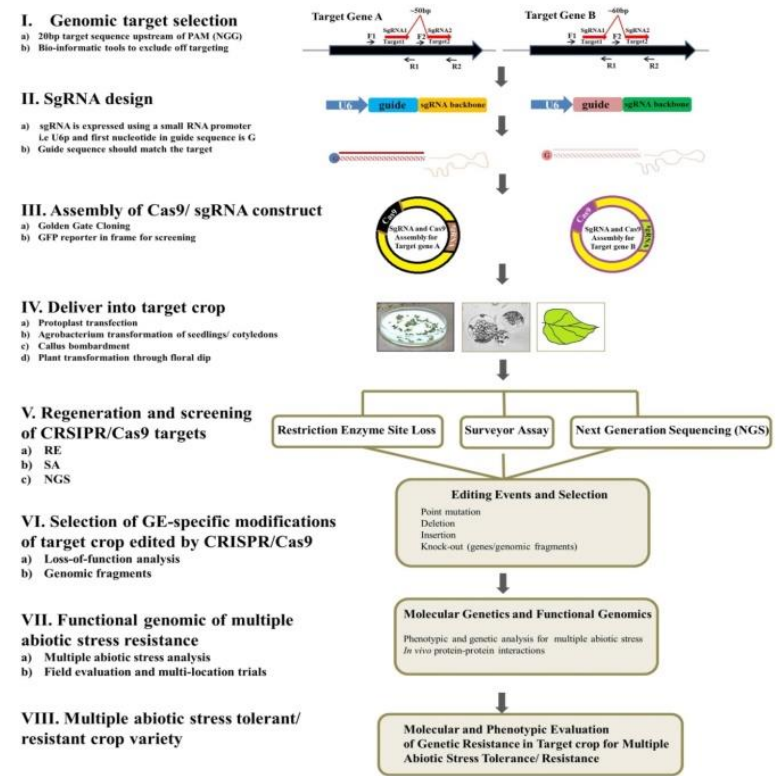

Fig 4. Schematic representation of development of multiple abiotic stress resistant/ tolerant crop plants using dual-gene multiplex CRISPR/Cas9 genome editing approach. Target specific editing of more than one negative regulatory DEAD-box RNA helicases through CRISPR/Cas9 genome editing approach would be ideal in developing multiple abiotic stress resistance in crop plants. Generating large deletions or even complete knock-outs is possible through multiplexing where two or more sgRNAs can be targeted for each gene. 
foveolata that suggest to use as a potential drug against Ebola Virus (EBOV) as EBOV mRNAs have 5'capping and structured 5' UTRs (Biedenkopf et al., 2017). Such recent research endeavors also highlighted the pharmacological properties of the DEAD box RNA helicases. It has been reported that recent studies in Arabidopsis thaliana have shown that loss of eIF4A DEAD-box gene leads to reduced lateral root formation, delayed flowering and abnormal ovule development which infer that eIF4A play essential role in growth and development of plant (Bush et al., 2015). eIF4A is a large protein family that comprises of eIF4A-I, eIF4A-II, and eIF4A-III proteins. eIF4A-I and eIF4A-II were sharing about $90-95 \%$ sequence homology. However eIF4A-III shows only $60 \%$ sequence similarity with the other two genes (Koroleva et al., 2009a; Andreou and Klostermeier, 2014). eIF4A-III has shown to interact with the EJC nuclear complex proteins like Magoh and Y14 which influence the mRNA translation (Chan et al., 2004; Koroleva et al., 2009b; Andreou and Klostermeier, 2013; Kovalev and Nagy, 2014; Bush et al., 2015). AtRH7 in Arabidopsis thaliana actively participate in mRNA biogenesis and plant growth as well (Bush et al., 2015; Huang et al., 2016). OsBIRHI gene has been reported to show RNA dependent ATPase and ATP dependent RNA unwinding activity (Zhu et al., 2015). Recombinant YdbR (ORF product from Bacillus subtilis) has been reported as an ATP independent RNA binding protein, and having RNA dependent ATPase activity (Li et al., 2008).

\section{Abiotic stress and the DEAD-box RNA helicases}

Abiotic stress is the negative influence of the environmental factors like light, temperature, water, soil salinity and heavy metals etc. in plants (Tuteja N, 2010; Asensi-Fabado et al., 2016). All living organisms encounter with such unfavourable conditions at any stage of their lifetime. Plants have specific mechanism to tolerate such stress conditions where various genes actively participate through signal transductions. Stress plays important role in plants to acquire plasticity and dedifferentiation state which helps plant to adapt themselves in severe climatic conditions (Vashisht et al., 2006; Barrero-Gil et al., 2013; Grafi and Barak, 2015). Till date a lot of researches have been done in abiotic stress and its effect on various plants which have revealed that somatic embryogenesis is induced by stress (Grafi and Barak, 2015). It has also been proven that abiotic stress induces dedifferentiation which is characterized by remodelling of chromatin structure into a transcriptionally active open conformation that may increase the expression of some stress responsive genes (Koroleva et al., 2009b; Grafi and Barak, 2015; Ma et al., 2016). When plants are exposed to abiotic stress conditions, some specific cell signaling events occur to activate transcription factors which bind to the promoter region of stress responsive genes to show either positive or negative regulation in abiotic stress (Gong et al., 2002; Kant et al., 2007; Barak et al., 2014; Asensi-Fabado et al., 2016). Therefore, various stress responsive genes can be studied in detail by observing conformational changes of chromatin structures of the plants growing in different stress environment. AMP (adenosine monophosphate) accumulation arises during stressed condition which inhibits the RNA binding and RNA unwinding activity of the DEAD box RNA helicases like Ded1p, Mss116p, and eIF4A in yeast (Yang et al., 2007; Putnam and Jankowsky, 2013). Whereas, other yeast DEAD-box genes like Sub2p and Dbp5p were not sensitive to AMP (Putnam and Jankowsky, 2013). Recent studies have shown that AtRH7 DEAD-box gene confers cold tolerance in Arabidopsis thaliana (Huang et al., 2016). Some of the DEAD-box genes mediate epigenetic gene silencing of the stress induced genes expression through RNA directed DNA methylation (RdDM) (Kant et al., 2007; Barak et al., 2014; Khan et al., 2014). Using model oilseed crop Brassica napus, our group has studied the differential expression analysis of genes involved in abiotic stresses (Havlickova et al., 2013; Keshavaiah et al., 2014). Our group was first to identify the evolutionary origins of Brassicaceae specific genes which are also associated with different abiotic stress responses in model plant Arabidopsis thaliana. We have identified the lineage specific genes (orphan genes) in Brassicaceae and shown that abiotic stress response is a major feature of these orphan genes (Donoghue et al., 2011). Our study provided a comprehensive analysis of the origins of LSGs in Arabidopsis thaliana that are restricted to the Brassicaceae family. The stress responsiveness was identified as a distinct feature of Brassicaceae-specific genes; where these LSGs were enriched for genes responsive to a wide range of abiotic stresses. The analysis allows the relative importance (and prevalence) of different evolutionary routes to the genesis of novel ORFs within lineages to be assessed. Insights regarding the functional roles of lineagespecific genes are further advanced through identification of enrichment for stress responsiveness in lineage-specific genes, highlighting their likely importance for environmental adaptation strategies (Donoghue et al., 2011).

\section{Multiple abiotic stress and the DEAD-box RNA helicases}

Plants perform some crucial role to reverse back to dedifferentiation state so that plants acclimate themselves to adverse climatic conditions through reduction of protein synthesis, conformational changes of chromatin and nucleolus structure (Barak et al., 2014; Grafi and Barak, 2014). Multiple abiotic stresses are the caustic reason for constant reduction in major crop productivity. Due to severe climatic changes all around the world, crop productivity has been relatively reduced which is really unfortunate for the globe. Though, many research activities have been put forwarded regarding the genes showing tolerance to the abiotic stress conditions, still the culmination of constructing stable multiple abiotic stress tolerant crops are yet to be achieved. The DEAD-box helicase genes are found to be active participants in abiotic stress tolerance in plants (Owttrim, 2006, Barak et al., 2014; Liu et al., 2014). Recently, a lot of studies have been carried out to offer an insight into the DEAD-box helicase genes which are involved in multiple abiotic stress response to exploit them in development of transgenic crop plants for the betterment of agricultural crop productivity under adverse climatic conditions (Liu et al., 2014. Although recent researches have revealed some of the DEAD-box genes which confer tolerance to abiotic stresses, but are mostly focused on single stress. Therefore, there is a plenty to unravel about DEADbox RNA helicases to acquire multiple abiotic stresses including salinity, cold and drought tolerance. Using the Arabidopsis and tomato as model plant and crop, respectively, our lab is elucidating the molecular and genetic mechanism associated with multiple abiotic stress responses using CRISPR/Cas9 genome editing and functional genomics approaches (on-going and unpublished work).

\section{Drought and the DEAD-box genes in model and crop plants}

Water is a key element for all living organisms and plants as well. Therefore, dearth of water may cause severe damage to plants which can be categorized into a major abiotic stress in 
environment. Drought stress leads to reduction of leaf expansion, root elongation and membrane damage (Farooq et al., 2010; Tuteja N, 2010). Rate of photosynthesis is diminished due to stomatal closure and ATP synthesis is perturbed by drought stress (Chaves et al., 2009; Farooq et al., 2010). Most of the plants mediate some complex mechanisms regulated by some specific genes and transcription factors to sustain the drought condition. Although there are lot of amino acids, osmolytes like glycine betaine and proline which show drought tolerance but there are certain DEAD-box genes that also provide drought tolerance to the plants (Owttrim, 2006; Tuteja N, 2010; Asensi-Fabado, et al. 2016). Number of research studies in model and crop plants has revealed that the DEAD-box genes are offering drought stress tolerance to the plants (Zhu et al., 2015). In spite of the fact that detailed study of the DEADbox genes have not done so far in tomato, a putative DEADbox gene namely SIDEAD31 has been reported to show drought tolerance and its over-expression also enhances the stress related genes expression (Zhu et al., 2015). Likewise, DREB1A/CBF3 shows drought tolerance in Arabidopsis thaliana and tomato plants respectively (Zhao et al., 2007). PDH45 (pea DNA helicase 45) over-expression enhances the up-regulation of DREB2-induced upstream stress responsive genes in sugarcane (Augustine et al., 2015). Using model oilseed crop Brassica napus, our group has studied the comparative analysis of protein/gene expression profiling in terms of time and duration of exposure to drought (Jelínkova, et al., 2014). We have characterized five Brassica napus dehydrin genes namely BnDHN1, ERD10, ERD15, Bn115 and COR25 and studied their behaviour in response to drought stress. Four Brassica napus varieties such as cadeli, viking, californium and navajo with significant differences in drought stress were selected. The results of expression analyses were discussed from the perspective of different strategies within varieties and in terms of gene expression. Dehydrin genes namely COR25, Bn115, ERD10, RCA and L$G U L$ have shown significant drought stress responses viking and cadeli cultivars of Brassica napus (Havlickova et al., 2013; Keshaviah et al., 2014).

\section{Salt stress and the DEAD-box helicase genes in model and crop plants}

Salt concentration is an essential component of soil for efficient plant growth. Though there are some plants which can survive under high salt concentration (halophytes), however increase in salt concentration show adverse effect on plants (glycophytes) which cannot survive beyond $250 \mathrm{mM}$ $\mathrm{NaCl}$ concentration (Tuteja, 2007). High salt concentration leads to $\mathrm{Na}^{+} / \mathrm{K}^{+}$ionic and osmotic imbalance which causes functional inhibition of important enzymes, membrane damage, and it might be even fatal (Tuteja, 2007; Zolla et al., 2010). In pea plant, mini-chromosome maintenance 6 (MCM6) gene has been reported to have helicase function and its over-expression confers salinity stress tolerance (Macovei et al., 2012). SIDEAD30, a tissue specific DEADbox gene and SIDEAD31, constitutively expressed DEADbox gene that shown tolerance to salinity stress conditions (Zhu et al., 2015). In Sorghum, the DEAD-box protein HVD1 from Hordeum vulgare which is an ATP dependent RNA helicase has reported to responsive to salinity stress (Macovei et al., 2012). In halophyte, dogbane plant $A v D H 1$ gene encoding a protein homologous to DEAD-box helicase shows salt-dependent expression and its expression was upregulated by cold stress. It has been reported that $A v D H 1$ was involved in $\mathrm{ABA}$ independent stress signaling pathway
(Macovei et al., 2012). P68, a putative DEAD-box helicase gene from pea plant has been found to responsive against salinity stress in transgenic tobacco plant (Tuteja et al., 2014). Using molecular genetics and cell biological approaches, we have functionally characterized the AtSKDl, a AAA-type ATPase associated with salt stress and its involvement in vacuolar maintenance in plants using Arabidopsis thaliana as a model plant (Shahriari et al., 2010). Apart from, adaptation to salt stress, the results shown that AtSKD1 contributes to vacuolar protein trafficking and thereby to the maintenance of the large central vacuole of plant cells, and their role in cell cycle maintenance (Jou et al., 2006; Shahriari et al., 2010).

\section{Cold stress and the DEAD-box helicase genes in model and crop plants}

Low temperature is another obstacle for adequate growth and development of various plants. Although there are some plants which have adaptive mechanism to extreme low temperature, scientists have been trying to generate cold tolerant plants by revealing the genes and their functions related to cold stress or other abiotic stresses. As an adaptive feature plants synthesize some cold induced proteins (CIPs) which helps the plant to bear the temperature below optimum level (Vashisht et al., 2005; Owttrim, 2006; Tuteja, 2010). Recently a DEAD-box RNA helicases AtRH7 from Arabidopsis thaliana has been found to be involved in cold tolerance mechanism (Liu et al., 2016). Arabidopsis thaliana COLD SHOCK DOMAIN PROTEIN 3 (AtCSP3) is a chaperone which is interacted with AtRH7 and this interaction plays important role in cold adaptation (Liu et al., 2016). LOS4 (Low expression of osmotically responsive genes 4) from Arabidopsis thaliana has shown as an active cold stress regulated gene (Gong et al., 2002; Vashisht et al., 2005; Owttrim, 2006). Expression of both LOS4 and AtRH7/PRH75 influence the expression of CBF1, CBF2 and CBF3 transcription factors proportionately which response to cold tolerance (Owttrim, 2006; Tuteja et al., 2014; Huang et al., 2016). Our studies resulted in quantification of expression and functional characterization of potential dehydrin genes in Brassica napus and to study their polymorphism in different cultivars in response to drought and cold stress. Significant cold stress response was observed from dehydrins COR25, Bn115, ERD10 and ERD15 in navajo, cadeli and californium cultivars. This will enable to develop specific markers based on drought and cold-induced dehydrin genes and their alleles involved in abiotic stress for improvement of practical plant breeding in Brassicaceae family (Keshavaiah et al., 2014).

\section{High temperature and the DEAD-box RNA helicase genes in model and crop plants}

Temperature is a crucial environmental factor for growth and development of plants and other living organisms as well. Optimum temperature for efficient growth varies from one species to another. Temperature plays a very important role in enzymatic reactions inside the plants. Therefore, fluctuation of temperature greatly hampers the internal crucial metabolisms of plants. Global warming has impaired the balance of the climatic factors. Most of the crop plants cannot withstand the extreme temperature conditions. High temperature causes dehydration, membrane damage and enzymatic inhibition in plants. But there are some genes which provide thermo tolerance to the plants. Recently a DEAD-box gene, TOGR1 (Thermo-tolerant Growth Required1) has been reported in rice to improve crop 
productivity with increase in expression under high temperature conditions and it also maintains rRNA homeostasis under heat stress (Wang et al., 2016). It has revealed that the RNA chaperon activity of the SSU associated nucleolar localized, TOGR1 as it participate to bring Pre-rRNAs back into functional conformation and also helps in proper RNA-protein interactions at high temperatures. SIDEAD31 mRNA expression level has been found to be increased in heat stress treatment in tomato plants which indicates tolerance to high temperature (Zhu et al., 2015). Cryophyte mutant of Arabidopsis thaliana having mutation in the DEAD-box gene identical to LOS4 gene has been reported to be sensitive to heat stress (Gong et al., 2005). Mutation in two DAED-box helicase genes stress response suppressor 1 (STRS1) and stress response suppressor 2 (STRS2) enhances the tolerance to heat stress along with other abiotic stresses like salt and osmotic stress in Arabidopsis thaliana. STRS1 and STRS2 have been found to suppress the expression of multiple abiotic stress responsive genes that confer abiotic stress tolerance to the plants (Kant et al., 2007; Khan et al., 2014).

\section{Other abiotic stresses and the DEAD-box RNA helicase genes in model and crop plants}

Apart from drought, salinity, cold and heat stress, there are several abiotic stresses that show adverse effect on plant growth and development. Plants mediate some complex mechanism also for such abiotic stresses like heavy metal stress, oxidative stress, poor edaphic condition, $\mathrm{pH}$ levels, and high radiation. Due to all these unfavourable environmental factors, total yield of major crop products have been decreasing in an abominable way. OsBIRH1 gene in rice encoding a DEAD-box RNA helicase, has been reported to show increased tolerance to oxidative stresses in rice and Arabidopsis thaliana (Zhu et al., 2015). Some other factors like reactive oxygen species (ROS) and inositol phosphates accumulates in plants under abiotic stress conditions (Owttrim, 2006; Tuteja, 2010). However, excess of ROS level causes damage to the plant cells. Over-expression of P68 has been reported to control the ROS accumulation under saline stress conditions (Tuteja et al., 2014).

\section{Multiple stress and the DEAD-box RNA helicase genes}

ATP binding protein (OsABP) is a DEAD-box helicase from rice which is found to be responsive to multiple abiotic stresses. OsABP has been found to be over-expressed under multiple stress conditions like saline condition, ABA treatment, dehydration condition, red and blue light. In silico studies of OsABP have shown that it also interacts with many important proteins which participate in RNA, DNA metabolism, mRNA biogenesis and stress tolerance (Macovei et al., 2012). PDH45 over-expression in transgenic sugarcane plants has been reported to confer salt and drought tolerance by enhancing the expression of the DREB2-upstream stress responsive genes (Augustine et al., 2015). SIDEAD30 and SIDEAD31 DEAD-box genes from tomato has been found to be effective against salinity, drought, cold, ABA stress conditions and also regulate the expression of other genes related to abiotic stress tolerance (Zhu et al., 2015). As phylogenetic studies have shown close relationship of SIDEAD3O and SIDEAD31 with AtRH36 and AtRH9 that infers functional similarities of these genes (Zhu et al., 2015). AtRH3 knockdown was resulted into the decrease in cold tolerance and saline conditions, and proper intron splicing is abrogated as the RNA chaperon activity of AtRH3 has been interrupted. Therefore, AtRH3 has found to be essential for growth, chloroplast function, 50s ribosome biogenesis, and stress tolerance in Arabidopsis thaliana model plant (Kant et al., 2007; Macovei et al., 2012). AtRH5, AtRH9 and AtRH25/STRS2 also show multiple abiotic stress responses (Kant et al., 2007; Huang et al., 2016). Hordeum vulgare DEAD-box protein (HVD1) in Sorghum was reported to be induced by salt as well as cold stress conditions (Macovei et al., 2012). Over-expression of OsBIRH1 has been reported to show tolerance to abiotic stress including oxidative stress in transgenic plants, and also to biotic stresses including pathogenic diseases ( $\mathrm{Li}$ et al., 2008). A member of immunophillin group of proteins, cyclophilins (CYP) which is available in various plants has shown to be responsive to multiple abiotic stress including salinity, cold, heat and drought, and protein-protein interaction has revealed that OsCYP-25 interacts with eIF-2 $\alpha$ DEAD-box RNA helicase (Gu et al., 2014). Likewise, some transcription factors play essential role in activation of abiotic stress responsive genes with the help of some promoter elements. DREBs (dehydration responsive element binding) are the transcription factors that confer adaptation against abiotic stress conditions by interacting with DRE/CRT cis-element (C-repeats) of the stress responsive gene promoter (Lata and Prasad, 2011; Trivedi et al., 2013). RD29A is a stress inducible promoter in Arabidopsis thaliana which has binding site for DREB1C. It has been reported that activation RD29A was regulated by cold stress condition, high salt and dehydration treatment using the $\mathrm{ABA}$ dependent and $\mathrm{ABA}$ independent transcription factors (Bihmidine et al., 2013). Recent research work has inferred that PgeIF4A gene expressing transgenic groundnut plants can exhibit tolerance to stress conditions (Santosh Rama Bhadra Rao et al., 2017). Transcription factor CBFs (cold binding factors) has also been found to be involved in cold tolerance and drought tolerance as well (Zhao et al., 2007; Tuteja, 2010; Trivedi et al., 2013). List of the DEAD-box RNA helicase genes showing their functional role in different abiotic stress responses in plants are represented in Table 1 .

\section{The DEAD-box RNA helicases as negative and positive regulators of abiotic stresses}

It can clearly be envisaged the functional involvement of DEAD-box genes in abiotic stress responses in plants from past research studies. Though DEAD-box helicase genes share conserved domain homology, they are functionally distinct. The DEAD-box genes can be categorized into positive and negative stress regulators. Stress response suppressor genes STRS1 and STRS2 are the DEAD-box helicase genes that show negative influence in abiotic stress responses in plants. STRS1 and STRS2 attenuate the expression of stress induced genes via RNA-directed DNA methylation but on exposure of plants to abiotic stress the STRSs activity was inhibited resuming the stress responsive expression (Barak et al., 2014) (Fig. 3). STRS1 and STRS2 have been considered as negative stress regulators as over expression of these genes confer reduced tolerance to abiotic stresses (Kant et al., 2007; Barak et al., 2014; Khan et al., 2014). Numerous transcription factors and proteins involved in abiotic stress response either via positive or negative regulation by assisting the function of the DEAD-box genes. DRD1, DC13 and RDR2 help STRS2 to perform RdDM whereas mutation in $H D 2 C$ gene lead to deformed localization of STRS1 under stresses (Luo et al., 2012; Khan et al., 2014; Yang et al., 2014). HD2C has been reported to be involved in salt, ABA stress tolerance by interacting with 
HDA6 which is responsive to cold stress (To et al., 2011). CBF5 also play important role in expression and localization of some DEAD-box genes like STRS1 and STRS2 (Khan et al., 2014). On the other hand eIF4A and AGO4 mutation do not effect STRSs localization which indicates their positive influence in plant stress response (Khan et al., 2014). DDB1, LHP1, AtRH9 and RD29A (responsive to dehydration 29A) have essential contribution to multiple abiotic stress responses (Kim et al., 2008; Exner et al., 2009; Lata and Prasad, 2011; To et al., 2011; Zhu et al., 2015). Complete list of the DEAD-box genes and transcription factors showing positive or negative regulation in abiotic stress responses are given in Table 2. Many RNA helicase genes are found to be regulated by stress, as, for example, the expression of DRH1 was moderately induced by cold stress (Macovei et al., 2012). Whereas, two RNA helicases EMB3108 and PDE340 from Arabidopsis thaliana has been reported to be down-regulated by cold, salt and osmotic stresses (Owttrim, 2006; Macovei et al., 2012). AtALY4 was an ortholog to NbALY916 and has been found to be involved in defence-related gene expressions in plants (Ly et al., 2013). SIDEAD31 has been found to be a positive regulator in stress response against multiple abiotic stress including salinity, drought, cold, ABA stress (Zhu et al., 2015).

\section{Current status in model and crop plants}

Due to global warming, lots of fluctuations have occurred on the climatic factors which are vital for plants. Plants acquire some adaptive features to withstand the adverse conditions. There are some adaptive mechanisms in plants which are regulated by various essential genes and transcription factors (Zhu et al., 2015). But most of the plants still lack such defense mechanism as they are devoid of those important genes and transcription factors. Genetic engineering has revolutionized the idea of inserting stress resistant genes from other organisms into plants to make them stress tolerant. Since abiotic stress has been a major factor for huge loss of crop productivity, innumerable researches have been done in abiotic stress tolerance in plants. Discovery of DEAD-box helicases was a breakthrough for researchers to develop stress tolerant crop plants. Basically, model plant systems are chosen to study genes responsive towards the stress conditions due to their experiment friendly characteristics. Arabidopsis thaliana, tobacco (Nicotiana benthamiana), pea plant (Pisum sativum), oilseed rape (Brassica napus) and many more model plants have been used for various research studies for stress biology. Recently, some important DEADbox genes have been reported to be involved in stress tolerance in some model and major crop plants. SIDEAD3O and SIDEAD31 DEAD-box genes from tomato have been reported to show salinity, drought, cold and ABA stress tolerance (Trivedi et al., 2015). Very recently, a DEAD-box gene TOGRl have been found to confer thermo tolerance to rice crop and this is the first plant DEAD-box RNA helicase which is found to improve crop yield under high temperature (Wang et al., 2016). Hordeum vulgare DEAD-box protein (HVD1) in sorghum has been reported to show tolerance to salt as well as cold stress conditions. In one of our recent book chapter, we have discussed the latest genomic technologies for different applications which can be utilized for abiotic stress study exploration in model and crop plants (McKeown et al., 2012). Our published, on-going and unpublished research in model and crop plants are focused on developing multiple abiotic stress tolerance in tomato crop model using a range of functional genomics and target specific (DEAD-box genes) multiplex genome editing
(CRISPR/Cas9) approaches. Target specific editing of more than one negative regulatory DEAD-box RNA helicases through CRISPR/Cas9 genome editing approach would be ideal in developing multiple abiotic stress resistance in crop plants. Generating large deletions or even complete knockouts are possible through multiplexing where two or more sgRNAs can be targeted for each gene. A scheme of development of multiple abiotic stress resistant/ tolerant crop plants using dual-gene multiplex CRISPR/Cas9 genome editing approach is presented in Fig. 4.

\section{Scope for future research and development}

The stated examples are only a small part of the whole scenario which is yet to be unveiled the detailed molecular structures and functional mechanisms of the DEAD-box RNA helicase genes. Since DEAD-box genes are extensively involved with RNA/DNA metabolisms, mRNA export, ribosome biogenesis and conformational changes of proteins, there is high possibility to reveal the other proteins or transcription factors which help the DEAD-box genes to mediate the specific functions. The stress response inducing proteins and the RNA targets that directly involved in the DEAD-box genes regulated stress response yet to be identified. More strategies could be planned to offer an insight into the mechanisms behind multiple abiotic stress response of the DEAD-box RNA helicase genes to develop crop production constancy, and to increase economic evolvement. Target specific multiplex and multigene CRISPR/Ca9 genome editing would be an ideal approach to edit different abiotic stress responsive DEAD-box RNA helicase genes to develop sustainable multiple abiotic stress tolerance in crop plants for sustainable crop productivity under multiple abiotic stress conditions to cope with rapidly changing global climate.

\section{Acknowledgements}

We would like to express our heartfelt gratitude to The Director, CSIR-NEIST, Jorhat. This work was supported by the Ramanujan Fellowship grant funded by Science \& Engineering Research Board (SERB), Department of Science and Technology, Govt. of India. Reference No. SR/S2/RJN078/2014; Project No. GAP0741. Authors have declared no conflict of interest.

\section{References}

Andreou AZ, Harms U, Klostermeier D (2017) eIF4B stimulates eIF4A ATPase and unwinding activities by direct interaction through its 7-repeats region. RNA Biol. 14(1):113-123.

Andreou AZ, Klostermeier D (2013) The DEAD-box helicase eIF4A: paradigm or the odd one out? RNA Biol. 10(1):19-32.

Andreou AZ, Klostermeier D (2014) eIF4B and eIF4G jointly stimulate eIF4A ATPase and unwinding activities by modulation of the eIF4A conformational cycle. J Mol Biol. 426(1):51-61.

Ando Y, Nakamura K (2006) Bacillus subtilis DEAD protein YdbR possesses ATPase, RNA binding, and RNA unwinding activities. Biosci Biotechnol Biochem. 70:16061615.

Asensi-Fabado MA, Amtmann A, Perrella G (2016) Plant responses to abiotic stress: the chromatin context of transcriptional regulation. Biochem Biophys Acta. 1860 (1):106-122. 
Augustine SM, Ashwin Narayan J, Syamaladevi DP, Appunu C, Chakravarthi M, Ravichandran V, Tuteja N, Subramonian N (2015) Introduction of pea DNA helicase 45 into sugarcane (Saccharum spp. hybrid) enhances cell membrane thermostability and upregulation of stressresponsive genes leads to abiotic stress tolerance. Mol Biotechnol. 57:475-488.

Barak S, Singh Yadav N, Khan A (2014) DEAD-box RNA helicases and epigenetic control of abiotic stress-responsive gene expression. Plant Signal Behav. 9(12):e977729.

Barrero-Gil J, Salinas J (2013) Post-translational regulation of cold acclimation response. Plant Sci. 205-206:48-54.

Biedenkopf N, Lange-Grünweller K, Schulte FW, Weißer A, Müller C, Becker D, Becker S, Hartmann RK, Grünweller A (2017) The natural compound silvestrol is a potent inhibitor of Ebola virus replication. Antiviral Res. 137:7681

Bihmidine S, Lin J, Stone JM, Awada T, Specht JE, Clemente TE (2013) Activity of the Arabidopsis RD29A and RD29B promoter elements in soybean under water stress. Planta. 237(1):55-64.

Bolinger C, Sharma A, Singh D, Yu L, Boris-Lawrie K (2010) RNA helicase A modulates translation of HIV-1 and infectivity of progeny virions. Nucleic Acids Res. 38(5):1686-96.

Bolinger C, Yilmaz A, Hartman TR, Kovacic MB, Fernandez S, Ye J, Forget M, Green PL, Boris-Lawrie K (2007) RNA helicase A interacts with divergent lymphotropic retroviruses and promotes translation of human $\mathrm{T}$-cell leukemia virus type 1. Nucleic Acids Res. 35(8):2629-42.

Bush MS, Crowe N, Zheng T, Doonan JH (2015) The RNA helicase, eIF4A-1, is required for ovule development and cell size homeostasis in Arabidopsis. Plant J. 84(5):9891004.

Chan CC, Dostie J, Diem MD, Feng W, Mann M, Rappsilber J, Dreyfuss G (2004) eIF4A3 is a novel component of the exon junction complex. RNA. 10(2):200-9.

Chaves MM, Flexas J, Pinheiro C (2009) Photosynthesis under drought and salt stress: regulation mechanisms from whole plant to cell. Ann Bot. 103(4):551-60.

Childs JJ, Gentry RC, Moore AF, Koculi E (2016) The DbpA catalytic core unwinds double-helix substrates by directly loading on them. RNA. 22(3):408-15.

Chu YD, Chen HK, Huang T, Chan SP (2016) A novel function for the DEAD-box RNA helicase DDX-23 in primary microRNA processing in Caenorhabditis elegans. Dev Biol. 409(2):459-72.

Donoghue MT, Keshavaiah C, Swamidatta SH, Spillane C (2011) Evolutionary origins of Brassicaceae specific genes in Arabidopsis thaliana. BMC Evol Biol. 11:47.

Exner V, Aichinger E, Shu H, Wildhaber T, Alfarano P, Caflisch A, Gruissem W, Köhler C, Hennig L. (2009) The chromodomain of like heterochromatin protein 1 is essential for $\mathrm{H} 3 \mathrm{~K} 27 \mathrm{me} 3$ binding and function during Arabidopsis development. PLoS One. 4(4):e5335.

Fairman-Williams ME, Guenther UP, Jankowsky E (2010) SF1 and SF2 helicases: family matters. Curr Opin Struct Biol. 20(3):313-24.

Farooq M, Kobayashi N, Ito O, Wahid A, Serraj R (2010) Broader leaves result in better performance of indica rice under drought stress. J Plant Physiol. 167(13):1066-75.

Gong Z, Dong CH, Lee H, Zhu J, Xiong L, Gong D, Stevenson B, Zhu JK (2005) A DEAD box RNA helicase is essential for mRNA export and important for development and stress responses in Arabidopsis. Plant Cell. 17:256-267.
Gong Z, Lee H, Xiong L, Jagendorf A, Stevenson B, Zhu JK (2002) RNA helicase-like protein as an early regulator of transcription factors for plant chilling and freezing tolerance. Proc Natl Acad Sci U S A. 99(17):11507-12.

Górna MW, Pietras Z, Tsai YC, Callaghan AJ, Hernández H, Robinson CV, Luisi BF (2010) The regulatory protein RraA modulates RNA-binding and helicase activities of the E. Coli RNA degradosome. RNA. 16(3):553-62.

Grafi G, Barak S (2014) Stress as a fundamental theme in cell plasticity. Biochem Biophys Acta. 1849(4):369-70.

Grafi G, Barak S (2015) Stress induces cell dedifferentiation in plants. Biochem Biophys Acta. 1849(4):378-84.

Gu L, Xu T, Lee K, Lee KH, Kang H (2014) A chloroplastlocalized DEAD-box RNA helicaseAtRH3 is essential for intron splicing and plays an important role in the growth and stress response in Arabidopsis thaliana. Plant Physiol Biochem. 82:309-18.

Halls C, Mohr S, Del Campo M, Yang Q, Jankowsky E, Lambowitz AM (2007) Involvement of DEAD-box proteins in group I and group II intron splicing. Biochemical characterization of Mss116p, ATP hydrolysisdependent and -independent mechanisms, and general RNA chaperone activity. J Mol Biol. 365(3):835-55.

Hardwick SW, Luisi BF (2013) Rarely at rest: RNA helicases and their busy contributions to RNA degradation, regulation and quality control. RNA Biol. 10(1):56-70.

Hartman TR, Qian S, Bolinger C, Fernandez S, Schoenberg DR, Boris-Lawrie K (2006) RNA helicase A is necessary for translation of selected messenger RNAs. Nat Struct Mol Biol. 13(6):509-16.

Havlickova L, Jelínková I, Chikkaputtaiah C, Munchausen I, Urban M; Curn V (2013) Study of the expression of genes associated with abiotic stress in rape. Úroda. 12:142--145.

Huang CK, Shen YL, Huang LF, Wu SJ, Yeh CH, Lu CA (2016) The DEAD-box RNA helicase AtRH7/PRH75 participates in pre-rRNA processing, plant development and cold tolerance in Arabidopsis. Plant Cell Physiol. 57(1):174-91.

Hilbert M, Kebbel F, Gubaev A, Klostermeier D (2011) eIF4G stimulates the activity of the DEAD box protein eIF4A by a conformational guidance mechanism. Nucleic Acids Res. 39(6):2260-70.

Jankowsky E (2011) RNA helicases at work: binding and rearranging. Trends Biochem Sci. 36(1):19-29.

Jankowsky E, Fairman-William ME (2007) RNA helicasesone fold for many functions. Curr Opin Struc Biol. 17(3):316-24.

Jankowsky E, Fairman-Williams ME (2010) An introduction to RNA helicases: superfamilies, families, and major Themes. In: Jankowsky E (ed) RNA helicases, RSC Biomolecular Sciences No. 19, Royal Society of Chemistry.

Jankowsky A, Guenther UP, Jankowsky E (2011) The RNA helicase database. Nucleic Acids Res. 39(Database issue):D338-41.

Jankowsky E, Putnam A (2010) Duplex unwinding with DEAD-box proteins. Methods Mol Biol. 587:245-64.

Jao LE, Akef A, Wente SR (2017) A role for Gle1, a regulator of DEAD-box RNA helicases, at centrosomes and basal bodies. Mol Biol Cell. 28(1):120-127.

Jarmoskaite I, Russell R (2014) RNA helicase proteins as chaperones and remodelers. Annu Rev Biochem. 83:697725 .

Jelínková I, Keshavaiah C, Havlíčková L., Vítámvás P Urban M (2014) Genů/proteinů indukovaných v podmínkách stresu suchem u řepky olejky. Comparative analysis of protein/gene expression profiling in terms of time and 
duration of exposure to drought in winter oilseed rape. Úroda. 12:187-190.

Jou Y, Chiang C-P, Jauh G-Y, Yen HE (2006) Functional characterization of ice plant SKD1, an AAA-Type ATPase associated with the endoplasmic reticulum-golgi network, and its role in adaptation to salt stress. Plant Physiol. 141(1):135-146.

Kant P, Kant S, Gordon M, Shaked R, Barak S (2007) Stress response suppressor1 and stress response suppressor2, two DEAD-box RNA helicases that attenuate Arabidopsis responses to multiple abiotic stresses. Plant Physiol. 145(3):814-830.

Keshavaiah C, Havlickova L Jelinkova I, Curn V (2014) Differential expression analysis of gene involved in abiotic stress in oil seed rapes. Expresní analýza genů zapojených $\mathrm{v}$ reakci na abiotický stres u řepky olejky. Úroda. 12:167170.

Khan A, Garbelli A, Grossi S, Florentin A, Batelli G, Acuna T, Zolla G, Kaye Y, Paul LK, Zhu JK, Maga G, Grafi G, Barak S (2014) The Arabidopsis stress response suppressor DEAD-box RNA helicases are nucleolar- and chromocenter-localized proteins that undergo stressmediated relocalization and are involved in epigenetic gene silencing. Plant J. 79(1):28-43.

Kim JS, Kim KA, Oh TR, Park CM, Kang H. (2008) Functional characterization of DEAD-box RNA helicases in Arabidopsis thaliana under abiotic stress conditions. Plant Cell Physiol. 49(10):1563-71.

Koroleva OA, Brown JW, Shaw PJ (2009a) Localization of eIF4A-III in the nucleolus and splicing speckles is an indicator of plant stress. Plant Signal Behav. 4(12):114851.

Koroleva OA, Calder G, Pendle AF, Kim SH, Lewandowska D, Simpson CG, Jones IM, Brown JWS, Shaw PJ (2009b) Dynamic behavior of Arabidopsis eIF4A-III, putative core protein of exon junction complex: fast relocation to nucleolus and splicing speckles under hypoxia. Plant Cell. 21(5): 1592-1606.

Kovalev N, Nagy PD (2014) The expanding functions of cellular helicases: the tombus virus RNA replication enhancer co-opts the planteIF4AIII-likeAtRH2 and the DDX5-like AtRH5 DEAD-box RNA helicases to promote viral asymmetric RNA replication. PLoS Pathog. 10(4):e1004051.

Lata C, Prasad M (2011) Role of DREBs in regulation of abiotic stress responses in plants. J Exp Bot. 62(14):473148.

Lehnik-Habrink M, Rempeters L, Kovács ÁT, Wrede C, Baierlein C, Krebber H, Kuipers OP, Stülke J (2013) DEAD-Box RNA helicases in Bacillus subtilis have multiple functions and act independently from each other. $\mathbf{J}$ Bacteriol. 195(3):534-44.

Leitão AL, Costa MC, Enguita FJ (2015) Unzippers, resolvers and sensors: a structural and functional biochemistry tale of RNA helicases. Int $\mathrm{J}$ Mol Sci. 16(2):2269-93.

Li D, Liu H, Zhang H, Wang X, Song F (2008) OsBIRH1, a DEAD-box RNA helicase with functions in modulating defence responses against pathogen infection and oxidative stress. J Exp Bot. 59(8):2133-46.

Li Y, Xiong R, Bernards M,Wang A (2016) Recruitment of Arabidopsis RNA helicase AtRH9 to the viral replication complex by viral replicase to promote turnip mosaic virus replication. Sci Rep. 6:30297.

Lin HC, Zhao J, Niland CN, Tran B, Jankowsky E, Harris ME (2016) Analysis of the RNA binding specificity landscape of $\mathrm{C} 5$ protein reveals structure and sequence preferences that direct RNase $\mathrm{P}$ specificity. Cell Chem Biol. 23(10):1271-1281.

Linder P, Jankowsky E (2011) From unwinding to clampingthe DEAD-box RNA helicase family. Nat Rev Mol Cell Biol. 12(8):505-16.

Linder P, Lasko PF, Ashburner M, Leroy P, Nielsen PJ, Nishi K, Schnier J, Slonimski PP (1989) Birth of the D-E-A-D box. Nature. 337(6203):121-2.

Liu F, Putnam AA, Jankowsky E (2014) DEAD-box helicases form nucleotide-dependent, long-lived complexes with RNA. Biochemistry. 53(2):423-33.

Liu Y, Tabata D, Imai R (2016) A Cold-inducible DEADBox RNA helicase from Arabidopsis thaliana regulates plant growth and development under low temperature. PLoS One. 11(4):e0154040.

Luo M, Wang YY, Liu X, Yang S, Lu Q, Cui Y, Wu K. (2012) HD2C interacts with HDA6 and is involved in ABA and salt stress response in Arabidopsis. J Exp Bot. 63(8):3297-306.

Ly V, Hatherell A, Kim E, Chan A, Belmonte MF, Schroeder DF. (2013) Interactions between Arabidopsis DNA repair genes UVH6, DDB1A, and DDB2 during abiotic stress tolerance and floral development. Plant Sci. 213:88-97.

Ma WK, Paudel BP, Xing Z, Sabath IG, Rueda D, Tran EJ (2016) Recruitment, duplex unwinding and proteinmediated inhibition of the DEAD-box RNA helicase Dbp2 at actively transcribed chromatin. J Mol Biol. 428(6):1091106.

Macovei A, Vaid N, Tula S, Tuteja N (2012) A new DEADbox helicase ATP-binding protein (OsABP) from rice is responsive to abiotic stress. Plant Signal Behav. 7(9):113843.

Mahajan S, Tuteja N (2005) Cold, salinity and drought stresses: an overview. Arch Biochem Biophys. 444(2):13958.

Mallam AL, Sidote DJ, Lambowitz AM (2014) Molecular insights into RNA and DNA helicase evolution from the determinants of specificity for a DEAD-box RNA helicase. Elife. 3:e04630.

McDaniel SL, Zweifel E, Harris PK, Yao MC, Cole ES, Chalker DL (2016) DRH1, a p68-related RNA helicase gene, is required for chromosome breakage in Tetrahymena. Biol Open. 5:1790-1798.

McKeown P, Keshavaiah C, Port A, Tuteja R, Chatterjee M, Varsney R and Spillane C (2012) Harnessing genomics to improve nutritional content and bioavailability of plantderived foods. In: P.S. Panesar and S.S. Marwaha (Eds). Biotechnology in Agriculture and Food Processing: Opportunities and Challenges. CRC Press (Taylor \& Francis Group), USA.

Mikhailova T, Shuvalova E, Ivanov A, Susorov D, Shuvalov A, Kolosov PM, Alkalaeva E (2017) RNA helicase DDX19 stabilizes ribosomal elongation and termination complexes. Nucleic Acids Res. 45(3):1307-1318.

Mohr G, Del Campo M, Mohr S, Yang Q, Jia H, Jankowsky E, Lambowitz AM (2008) Function of the C-terminal domain of the DEAD-box protein Mss116p analyzed in vivo and in vitro. J Mol Biol. 375(5):1344-64.

Owttrim GW (2006) RNA helicases and abiotic stress. Nucleic Acids Res. 34:3220-3230.

Owttrim GW (2013) RNA helicases: diverse roles in prokaryotic response to abiotic stress. RNA Biol. 10:96110.

Padmanabhan PK, Zghidi-Abouzid O, Samant M, Dumas C, Aguiar BG, Estaquier J, Papadopoulou B (2016) DDX3 DEAD-box RNA helicase plays a central role in mitochondrial protein quality control in Leishmania. Cell 
Death Dis. 7(10): e2406.

Pascuan C, Frare R, Alleva K, Ayub ND, Soto G (2016) mRNA biogenesis-related helicase eIF4AIII from Arabidopsis thaliana is an important factor for abiotic stress adaptation. Plant Cell Rep. 35:1205-1208.

Putnam AA, Jankowsky E (2013) AMP sensing by DEADbox RNA helicases. J Mol Biol. 425:3839-3845.

Pyle AM (2008) Translocation and unwinding mechanisms of RNA and DNA helicases. Annu Rev of Biophys. 37:317336.

Ranji A, Boris-Lawrie K (2010) RNA helicases: emerging roles in viral replication and the host innate response. RNA Biol. 7:775-787.

Ranji A, Shkriabai N, Kvaratskhelia M, Musier-Forsyth K, Boris-Lawrie K (2011) Features of double-stranded RNAbinding domains of RNA helicase A are necessary for selective recognition and translation of complex mRNAs. J Biol Chem. 286:5328-5337.

Ruminski DJ, Watson PY, Mahen EM, Fedor MJ (2016) A DEAD-box RNA helicase promotes thermodynamic equilibration of kinetically trapped RNA structures in vivo. RNA. 22(3):416-27.

Santosh Rama Bhadra Rao T, Vijaya Naresh J, Sudhakar Reddy P, Reddy MK, Mallikarjuna G (2017) expression of pennisetum glaucum eukaryotic translational initiation factor 4A (PgeIF4A) confers improved drought, salinity, and oxidative stress tolerance in groundnut. Front Plant Sci. 8:1-15.

Shahriari M, Keshavaiah C, Scheuring D, Sabovljevic A, Pimpl P, Häusler RE, Hülskamp M, Schellmann S (2010) The AAA-type ATPase AtSKD1 contributes to vacuolar maintenance in Arabidopsis thaliana. Plant J.64:71-85.

Tanner NK, Linder P (2001) DExD/Hbox RNA helicases: from generic motors to specific dissociation functions. Mol Cell. 8(2):251-62.

Teng W, Zhang H, Wang W, Li D, Wang M, Liu J, Zhang H, Zheng X, Zhang Z. (2014) ALY proteins participate in multifaceted Nep1Mo-triggered responses in Nicotiana benthamiana. J Exp Bot. 65:2483-2494.

To TK, Nakaminami K, Kim JM, Morosawa T, Ishida J, Tanaka M, Yokoyama S, Shinozaki K, Seki M. (2011) Arabidopsis HDA6 is required for freezing tolerance. Biochem Biophys Res Commun. 406:414-419.

Trivedi DK, Ansari MW, Tuteja N (2013) Multiple abiotic stress responsive rice cyclophilin: (OsCYP-25) mediates a wide range of cellular responses. Commun Integr Biol. 6(5):e25260.
Tuteja N (2007) Mechanisms of high salinity tolerance in plants. Methods Enzymol.428: 419-438.

Tuteja, N (2010) Cold, salinity, and drought stress, in plant stress biology: from genomics to systems biology (ed $\mathrm{H}$. Hirt), Wiley-VCH Verlag GmbH \& Co. KGaA, Weinheim, Germany.

Tuteja N, Banu MSA, Huda KMK, Gill SS, Jain P, Pham XH, Tuteja R (2014) Pea p68, a DEAD-Box helicase, provides salinity stress tolerance in transgenic tobacco by reducing oxidative stress and improving photosynthesis machinery. PLoS One. 9:e98287.

Vashisht AA, Pradhan A, Tuteja R, Tuteja N (2005) Coldand salinity stress-induced bipolar pea DNA helicase 47 is involved in protein synthesis and stimulated by phosphorylation with protein kinase C. Plant J Cell Mol Biol. 44:76-87.

Wang D, Qin B, Li X, Tang D, Zhang Y, Cheng Z, Xue Y (2016) Nucleolar DEAD-box RNA helicase TOGR1 regulates thermotolerant growth as a pre-rRNA chaperone in rice. PLoS Genet. 12(2):e1005844.

Yang CF, Chen KC, Cheng YH, Raja JA, Huang YL, Chien WC, Yeh SD (2014) Generation of marker-free transgenic plants concurrently resistant to a DNA geminivirus and a RNA tospovirus. Sci Rep.4:5717.

Yang Y, Sun Z, Ding C, Ge L, Sun L, Bai M, Song Y, Chen S, An L. (2014) A DEAD-boxRNA helicase produces two forms of transcript that differentially respond to cold stress in a cryophyte (Chorispora bungeana). Planta. 240:369380.

Yang Q, Del Campo M, Lambowitz AM, Jankowsky E (2007) DEAD-box proteins unwind duplexes by local strand separation. Mol Cell.28:253-263.

Yang Q, Jankowsky E. (2005) ATP- and ADP-dependent modulation of RNA unwinding and strand annealing activities by the DEAD-box protein DED1. Biochemistry. 44:13591-13601.

Yu E, Owttrim GW (2000) Characterization of the cold stress-induced cyanobacterial DEAD-box protein CrhC as an RNA helicase. Nucleic Acids Res. 28:3926-3934.

Zhao J, Ren W, Zhi D, Wang L, Xia G (2007) Arabidopsis DREB1A/CBF3 bestowed transgenic tall fescue increased tolerance to drought stress. Plant Cell Rep. 26:1521-1528.

Zhu M, Chen G, Dong T, Wang L, Zhang J, Zhao Z, Hu Z (2015) SIDEAD31, a putative DEAD-box RNA helicase gene, regulates salt and drought tolerance and stress-related genes in tomato. PLoS One. 10:e0133849.

Zolla G, Heimer YM, Barak S (2010) Mild salinity stimulates a stress-induced morphogenic response in Arabidopsis thaliana roots. J Exp Bot. 61:211-224. 